\title{
Thermomechanical Behavior of Late Indo-Chinese Granodiorite under High Temperature and Pressure
}

\author{
Yanjun Zhang, ${ }^{1,2}$ Shuren Hao $\mathbb{D D}^{1},{ }^{1}$ Lin Bai $\mathbb{D}^{\mathrm{D}},{ }^{3}$ Ziwang Yu, \\ Jianing Zhang, ${ }^{1}$ and Jingtao Fang ${ }^{4}$ \\ ${ }^{1}$ College of Construction Engineering, Jilin University, Changchun 130026, China \\ ${ }^{2}$ Key Laboratory of Groundwater Resource and Environment, Ministry of Education, Jilin University, Changchun 130026, China \\ ${ }^{3}$ College of Applied Technology, Jilin University, Changchun 130026, China \\ ${ }^{4}$ Geological Survey Institute of Liaoning Province, No. 42, Ningshan Middle Road, Huanggu District, Shenyang City, \\ Liaoning Province, China
}

Correspondence should be addressed to Shuren Hao; 540668136@qq.com and Lin Bai; 852699242@qq.com

Received 5 September 2017; Revised 25 December 2017; Accepted 1 January 2018; Published 1 February 2018

Academic Editor: Phillips O. Agboola

Copyright (C) 2018 Yanjun Zhang et al. This is an open access article distributed under the Creative Commons Attribution License, which permits unrestricted use, distribution, and reproduction in any medium, provided the original work is properly cited.

\begin{abstract}
This study investigates the influence of temperature, effective stress, and rock fracture on the bulk modulus and Biot's coefficient of granodiorite from a hot dry rock geothermal reservoir using the triaxial compression test. Three types of representative granodiorite samples were chosen for comparative experiments. The experiments were conducted with 0-55 MPa effective stress under cyclic loading. Results show that bulk modulus can continuously increase with the increase in effective stress at a constant temperature. The influencing law on Biot's coefficient is opposite that on bulk modulus. Interestingly, the temperature effects on the drained bulk modulus and Biot's coefficient depend on the effective stress. With regard to rock fractures, temperature and effective stress exert similar effects on the Biot's coefficients and bulk moduli of the samples compared with those of intact rock. The data of this experiment have a wide range of applications because most of the reservoir rocks in dry-hot-rock geothermal system have lithology of granite or granodiorite. The change law of rock modulus and Biot's coefficient with the temperature and pressure in this experiment provide the data basis for the future simulation calculation making the considered factors more comprehensive and the results closer to the real situation.
\end{abstract}

\section{Introduction}

The thermomechanical response of saturated porous rock under the influences of temperature, effective stress, and rock fracture offers great significance for field work. In particular, the change law of the parameters under these factors provides a good reference for the disposal of greenhouse gas and exploration of petroleum, natural gas, and hot dry rock resources. For example, when exploiting hot dry rock, the change in a rock mass's temperature and pore pressure can alter Biot's coefficient and cause the redistribution of the gravity field [1]. For another, injection of cooling $\mathrm{CO}_{2}$ into the deep ground will causes the decrease of vertical effective stress and thus change Biot's coefficient promoting the reduction of the porosity [2].
By triaxial compression tests, Handin et al. [3] point out the rock's mechanical deformation characteristics are related to rock porosity. Song and Renner [4] and Fabricius [5] studied Fontainebleau sandstone and showed that rock Biot's coefficient varies with the change in rock porosity. Furthermore, Ramos da Silva et al. [6] proposed a fitting relationship between Biot's coefficient and the porosity of saturated limestone. This relationship indicated the increase in Biot's coefficient with increase in rock porosity. However, altering the temperature not only changes stress but also modifies the physical properties of rock, including the rock bulk modulus and thermal expansion coefficient. Such effects generate nonlinear rock physical properties [7-10]. The nonisothermal triaxial compression experiment of Gallesville sandstone and Feichtinger sandstone has been performed by Blacic et al. [11] 
and Alireza et al. [12]. Both of the studies show that the thermomechanical parameters of rock mass, such as Biot's coefficient, bulk modulus, Young's modulus, and Poisson's ratio, are affected by temperature and effective stress. The presence of rock fracture is one of the important influences that cause the rock anisotropy. For cracked rock, Goodman et al. [13] proposed an equivalent continuum model of fractured rock mass. And a series of calculation models of fractured rock deformation are established. Equivalent medium parameters are used to describe rock deformation characteristics [14, 15]. Experimental and numerical studies [16-18] also showed that the fractured rock conditions caused a substantial effect on Biot's coefficient, rock bulk modulus, and other mechanical parameters. However, there is less study on the equivalent deformation parameters of fractured rock under nonisothermal condition.

Numerical simulation is an important technical means for studying and predicting the engineering problem of carbon dioxide geological reservoirs, nuclear waste disposal, dry rock development, and other deep rock mechanics problems [19-23]. Accurately obtaining the rock parameters is the key factor to obtain the accurate simulation results. However, in most of current simulations, the rock parameters are assumed to be constant [19, 20, 22-24]. However, during the exploitation of deep geological resources, parameters of the rock, such as rock bulk modulus and Biot coefficient, will change due to the change of temperature and pressure, thus leading to the numerical simulation results deviate from the true value if we ignore these features [25]. Bai [26] studied the change law of Biot coefficient of reservoir sandstone form a typical $\mathrm{CO}_{2}$ geological storage site at Ordos of China, under different temperature and pressure conditions and applied it to the numerical simulation of formation deformation of the site, finding the simulation result more close to the measured data. However, during the development of dryhot rocks, the change of the strata stress has more obvious influence on the bulk modulus and Biot coefficient of rocks, especially the fractured $[23,24]$. The late Indo-granodiorite was selected for the investigation, because it is similar to the geothermal reservoir rock found in China's first hot dry rock target area, specifically, the Gonghe Basin of Qinghai. More importantly, the lithology of reservoir rock in most dry-hot rock sites in the world is granite or granodiorite $[19-23,27]$. Therefore, the rock used in this experiment is very representative.

Given the problems mentioned above, the influences of temperature, effective stress, and rock fracture on bulk modulus and Biot's coefficient were investigated in this study aiming at experimentally quantifying the influence. To simulate the actual effective stress and pore stress of underground rock, which is usually caused by the injection of water into and out of reservoirs, the temperature was set to increase gradually, and circular loading and unloading axial pressures and confining pressure were applied under constant temperature [28].

To simulate the actual effective stress and pore stress of underground rock, which is usually caused by the injection of water into and out of reservoirs, the temperature was set to increase gradually, and circular loading and unloading axial pressures and confining pressure were applied under constant temperature [28].

\section{Theoretical Background}

2.1. Theory of Rock Elasticity under the Influence of Pressure and Temperature. Under drainage conditions, temperature alters the thermal expansion and pore fluid quality of rock mass as follows:

$$
\varepsilon=\frac{P_{e}}{K_{d}}-\beta_{b}\left(T-T_{0}\right),
$$

where $\varepsilon$ is the volume strain, $T_{0}$ is the initial temperature, $T-T_{0}$ is the change in temperature, $\beta_{b}$ is the volume thermal expansion coefficient of solid skeleton, $P_{e}$ is the effective pressure, and $K_{d}$ is the bulk modulus of drainage.

According to the principle of effective stress, $P_{e}$ and the effective stress $\sigma_{i j}^{\text {eff }}$ can be obtained using the following equation:

$$
\begin{gathered}
P_{e}=P-\alpha p \\
\sigma_{i j}^{\text {eff }}=\sigma_{i j}-\alpha p \delta_{i j},
\end{gathered}
$$

where $\sigma_{i j}^{\text {eff }}$ is the effective stress; $\sigma_{i j}$ is the total stress; $P$ is the pore water pressure; $p$ is the Kronecker constant, which takes the value of either 0 or 1 ; and $\alpha$ is Biot's coefficient, which can be defined as the efficiency of the pore fluid in rock in counteracting the external total stress.

The concept of effective stress is described by Berryman [29] and Gueguen [30], in different fields. The study of Zimmerman [31] provided a theoretical basis on analyzing the influence of Terzaghi effective stress on the effective rock bulk modulus. Bouteca [32] and Hart (1998) yielded similar conclusions after experimentation. Therefore, the expression of pressure and effective stress herein is based on Terzaghi's law. The Terzaghi law is derived from energetics; therefore, the effects of effective stress and temperature on Biot's coefficient can be analyzed from the perspective of energy.

The fluid mass heat $\beta_{m}$ was calculated using the coefficients of thermal expansion of pore fluid $\beta_{f}$ and $\beta_{p}$ as follows:

$$
\begin{aligned}
\beta_{m} & =\frac{1}{m}\left(\frac{\partial m}{\partial T}\right)_{P, p}=\frac{1}{\rho_{f}}\left(\frac{\partial \rho_{f}}{\partial T}\right)_{P, p}+\frac{1}{\phi}\left(\frac{\partial \phi}{\partial T}\right)_{P, p} \\
& =\beta_{p}-\beta_{f},
\end{aligned}
$$

where $\rho_{f}$ is the fluid density, $\phi$ is the porosity, $p$ is the pore water pressure, and $m$ is the ratio of fluid mass content $(M f)$ to the total rock mass $\left(v_{b}^{0}\right)$ with the same density. Normally, $\beta_{p}$ is smaller than $\beta_{f}$, implying that $m$ is negative, which indicates that the fluid mass decreases with an increase in temperature. The change in pore fluid quality is affected not only by temperature but also by the changes in pore pressure and rock deformation.

$$
\begin{aligned}
\Delta m & =m-m_{0} \\
& =-\alpha \rho_{f}^{0} \varepsilon+\frac{\alpha \rho_{f}^{0} p}{B K_{u}}+\left(\emptyset \beta_{m}-\alpha \beta_{b}\right) \rho_{f}^{0}\left(T-T_{0}\right),
\end{aligned}
$$


TABLE 1: Composition of the granodiorite samples from the Jilin Monkey Ridge area and the Gonghe Basin of Qinghai.

\begin{tabular}{lcccccccc}
\hline \multirow{2}{*}{ Area } & & \multicolumn{4}{c}{ The relative contents of minerals (\%) } & & \\
& Quartz & Alkali feldspar & Anorthose & Calcite & Amphibole & Andreattite & Kaolinite & Chlorite \\
\hline Gonghe Basin & 39 & 14 & 18 & 1 & 2 & 18 & 4 & 4 \\
Monkey Ridge & 27 & 18 & 26 & 0 & 0 & 29 & 0 \\
\hline
\end{tabular}

where $\rho_{f}^{0}$ is the density in the initial state, $B$ is the Skempton pore pressure parameter, and $K_{u}$ is the nondrainage volume modulus. The pore pressure change rate and confining pressure are related to the changes in confining pressure in the nondrainage experiment. Equations (4) and (5) describe the change law of the heating expansion of the rock pore fluid, and the heating expansion of rock is related to the rock solid particles and the rule of thermal expansion of the skeleton. The rock is composed of a variety of minerals; hence, the solid thermal expansion coefficient of rock can be calculated using the coefficient of thermal expansion of the composition [3335]. For example, in a solid phase composed of two kinds of minerals, the coefficient of thermal expansion $\left(\beta_{s}^{\text {eff }}\right)$ can be estimated by the following equation:

$$
\begin{aligned}
\beta_{s}^{\mathrm{eff}}= & f_{1} \beta_{1}+f_{2} \beta_{2} \\
& +\frac{1 / K_{s}-\left(f_{1} / K_{1}-f_{2} / K_{2}\right)}{1 / K_{2}-1 / K_{1}}\left(\beta_{2}-\beta_{1}\right),
\end{aligned}
$$

where $K_{i}$ and $\beta_{i}$ are the bulk modulus and the coefficient of thermal expansion of $i$ components, respectively. Campanella and Mitchell [36] believed that the coefficient of thermal expansion of rock matrix $\beta_{b}$ is equivalent to the coefficient of the thermal expansion of solid particles $\beta_{s}$. Palciauskas and Domenico [37] argued that the coefficient of thermal expansion of rock matrix $\beta_{b}$ is related to the coefficient of the thermal expansion of solid particles $\beta_{s}$ and the coefficient of thermal expansion of pore fluid $\beta_{p}$.

$$
\beta_{b}=(1-\phi) \beta_{s}+\phi \beta_{p} .
$$

The volume change of rock pore fluid and solid particles differs with varying effective pressure and temperature. Consequently, rock parameters, such as bulk modulus and Biot's coefficient, change correspondingly.

Biot's coefficient is calculated as follows

$$
\alpha=1-\frac{K_{d}}{K_{s}},
$$

where $\alpha$ is Biot's coefficient, $K_{d}$ is the rock drainage volume modulus, and $K_{s}$ is the drainage volume modulus of the rock solid particle skeleton. The calculation formula of bulk modulus is as follows:

$$
K=\frac{E}{3(1-2 \mu)},
$$

where $E$ is the rock Young's modulus and $\mu$ is the rock Poisson's ratio. The stress-strain curve can be generated to obtain the bulk modulus. Through the drainage and nondrainage tests, the rock drainage volume modulus $K_{d}$ and the drainage volume modulus of rock solid particle skeleton $K_{s}$ can be measured. These variables can be entered into (8) to calculate for Biot's coefficient.

Han et al. [15] derived the equivalent elastic modulus and equivalent Poisson's ratio based on the assumption that the rock block is isotropic elastic body and the stress and displacement of the fracture meet the linear relationship. The equivalent elastic modulus and equivalent Poisson's ratio are expressed as

$$
\begin{aligned}
& \widehat{E}=\left(\frac{1}{E}+\frac{\cos ^{4} \varphi}{s_{m} k_{n}}+\frac{\sin ^{2} \varphi \cos ^{2} \varphi}{s_{m} k_{s}}\right)^{-1} \\
& \widehat{\mu}=\frac{\widehat{E} \mu}{E}+\frac{\widehat{E}\left(k_{n}-k_{s}\right) \sin ^{2} \varphi \cos ^{2} \varphi}{2 s_{m} k_{n} k_{s}},
\end{aligned}
$$

where $\widehat{E}$ and $\widehat{\mu}$ are equivalent modulus and equivalent Poisson's ratio of the fractured rock. $k_{n}$ and $k_{s}$ are the normal stiffness and the tangential stiffness of the fracture. $s_{m}$ is the fracture spacing, and $\varphi$ is the angle of the fracture.

\section{Test Sample, Test Instruments, and Test Steps}

\subsection{Test Sample}

3.1.1. Selection of Test Sample. The cost of sampling in the Gonghe Basin of Qinghai is high because of the area's deep reservoir. Therefore, all samples (granodiorite) used in our experiment were extracted from the late Indo-China samples in the Jilin Monkey Ridge area, the properties of which are highly similar to those in the Gonghe Basin. We compared the two samples in terms of four different properties to verify whether the substitution was valid or not. The results of the composition analysis by X-ray diffraction and scanning electron microcopy (SEM) are shown in Table 1 and Figure 1.

The results show the high similarity between the two samples. Few obvious pores were observed; flaky and granular minerals were both found in the two samples, indicating that rock illite or illite/smectite was present in the two areas. Furthermore, quartz mineral was observed under a higher magnification.

Through density, wave velocity, porosity, and permeability, we compared the degree of compaction of the two samples and specific parameters are shown in Table 2

As shown in Figure 2, the two samples were characterized by fine-grained granite structure and massive structure. The mineral assemblages suggest that the two samples were acidic rocks, whereas the rock crystal structure indicates that the two samples were plutonic. The displayed alteration in 
TABLE 2: Rock parameters of the granodiorite samples from the Jilin Monkey Ridge area and the Gonghe Basin of Qinghai.

\begin{tabular}{lccccc}
\hline Area & $\begin{array}{c}\text { Dens } \\
\left(\mathrm{g} / \mathrm{cm}^{2}\right)\end{array}$ & $\begin{array}{c}S \text {-wave velocity } \\
(\mathrm{km} / \mathrm{s})\end{array}$ & $\begin{array}{c}\text { P-wave velocity } \\
(\mathrm{km} / \mathrm{s})\end{array}$ & $\begin{array}{c}\text { Porosity } \\
(\%)\end{array}$ & $\begin{array}{c}\text { Permeability } \\
\left(10^{-3} \mathrm{um}^{2}\right)\end{array}$ \\
\hline Gonghe Basin & 2.67 & 2.683 & 3.968 & $1.89 \%$ & 0.0312 \\
Monkey Ridge & 2.56 & 2.229 & 3.379 & $2.67 \%$ & 0.0627 \\
\hline
\end{tabular}
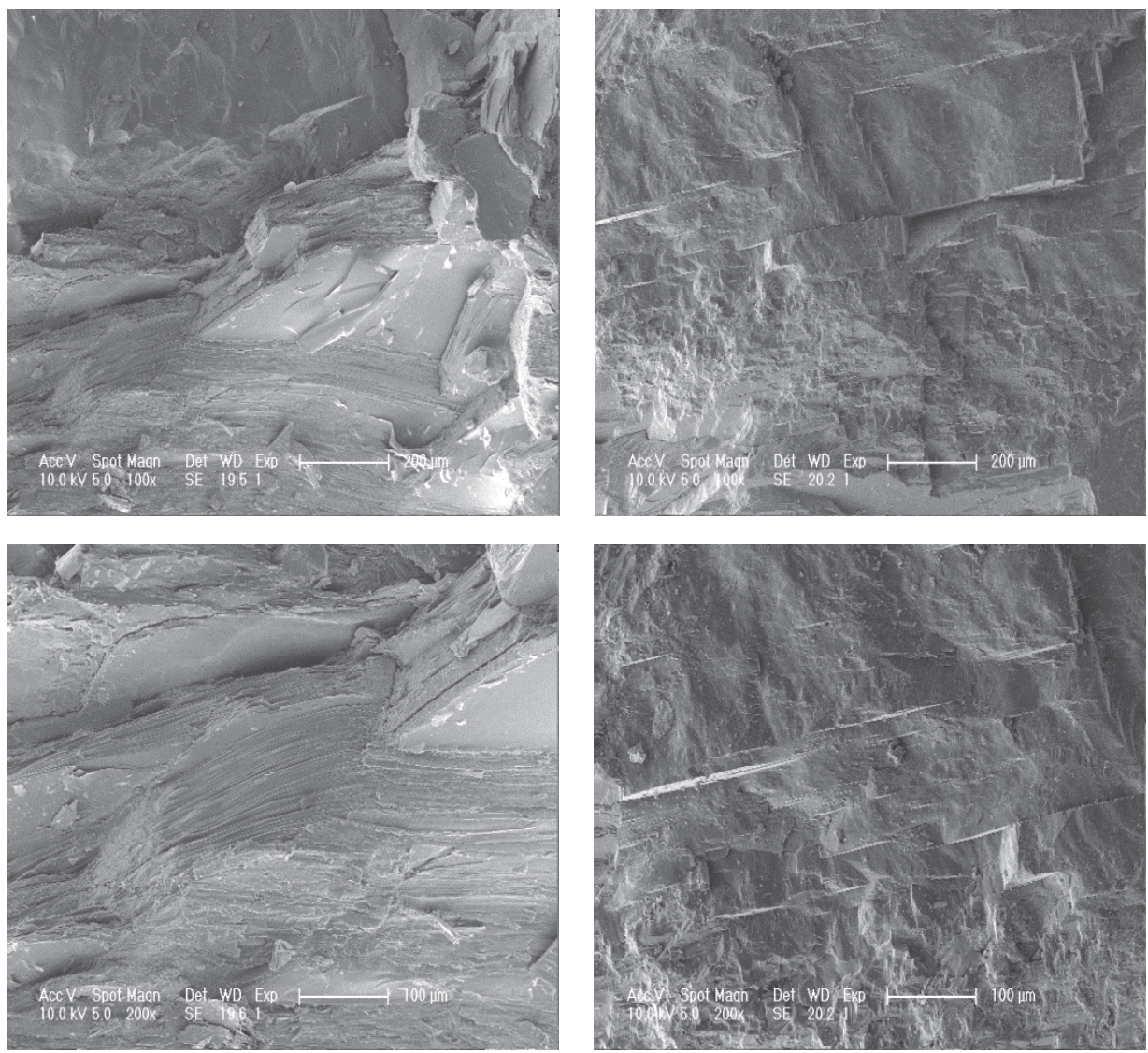

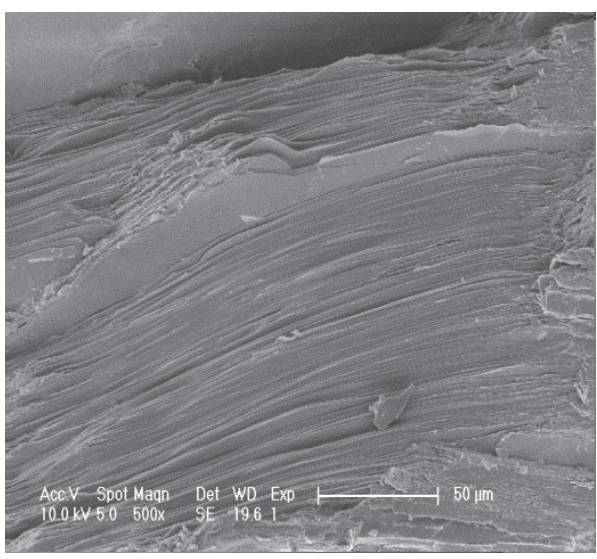

(a)

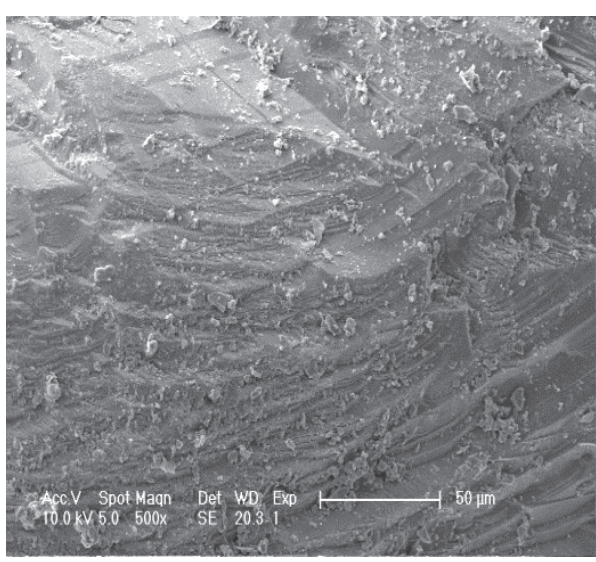

(b)

FIGURE 1: SEM of the granodiorite. (a) Jilin Monkey Ridge sample and (b) Gonghe Basin of Qinghai sample. 

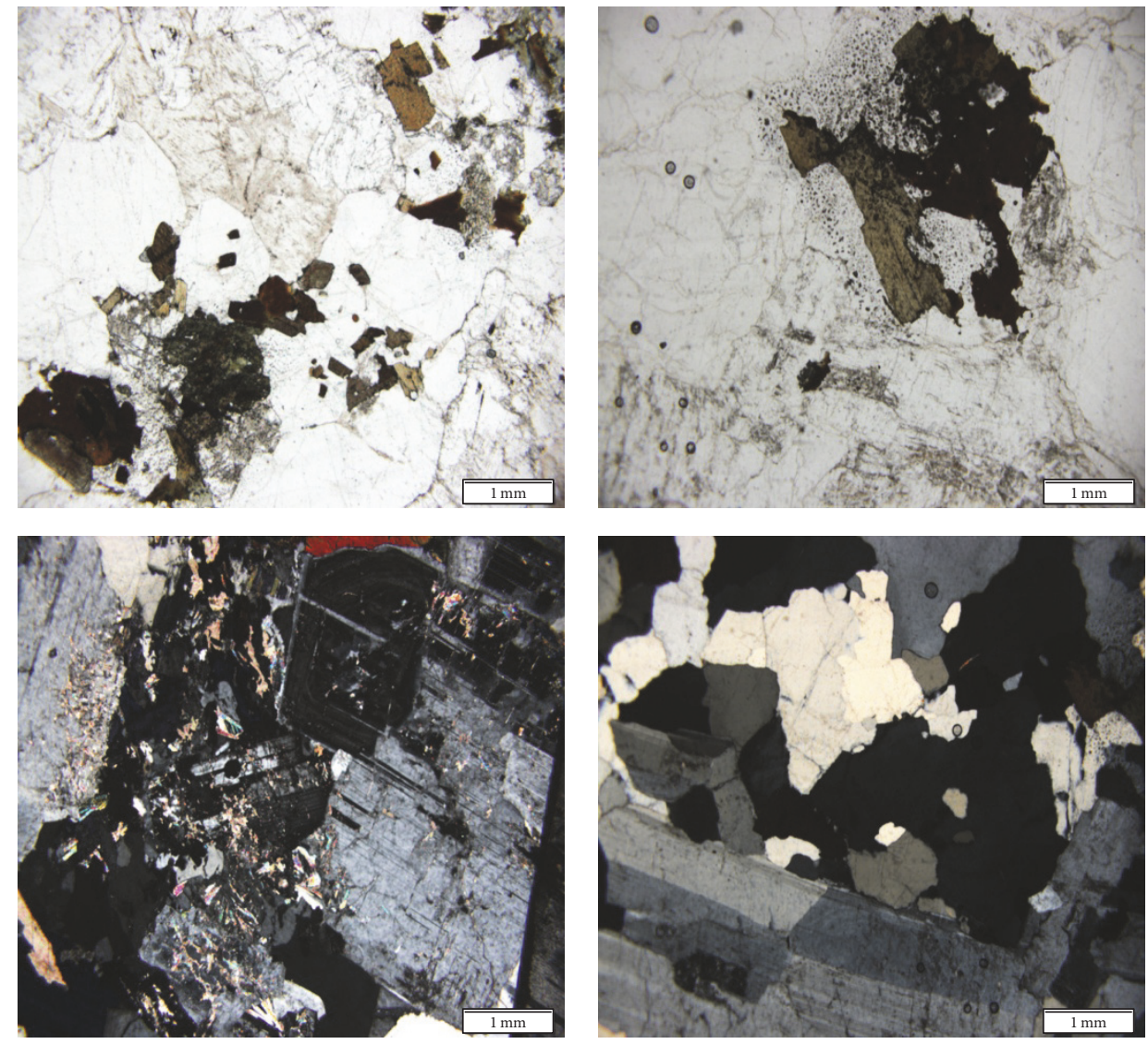

(a)

(b)

FIgURE 2: Polarizing micrographs of the granodiorite. (a) Jilin Monkey Ridge sample and (b) Gonghe Basin of Qinghai sample.

characteristics indicates that the two samples were affected by late hydrothermal conditions.

The comparison results show the validity of the substitution of the samples from the Gonghe Basin with those extracted from the late Indo-China area. The results obtained from our research can be used in exploiting other hot dry rock reservoirs.

3.1.2. Test Samples and Groups. The trial used three sets of samples divided into intact undisturbed granodiorite and artificial vertical and horizontal fractured granodiorite (Figure 3).

3.2. Test Instruments. In this paper, the traditional triaxial test was applied to achieve the research goals. In the process, a TAW-2000 computer control servo triaxial rock testing machine was employed as is shown in Figure 4. The instrument constantly monitored the rock deformation during the experiment. The pore water pressure, rock elastic modulus, and Poisson's ratio were also accurately measured.

The machine consisted of test, pressing, and control sections (Figure 5). The test section was composed of a test cavity with a lumen of $180 \mathrm{~mm}$ diameter and a cylinder of

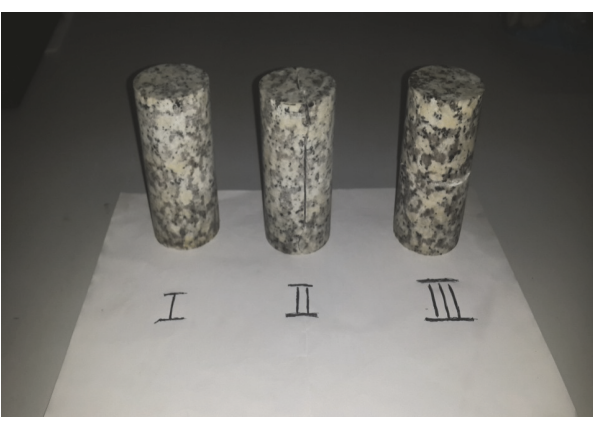

FIGURE 3: Rock samples. I: complete undisturbed granodiorite, II: artificial vertical fractured granodiorite, and III: artificial horizontal fractured granodiorite.

$380 \mathrm{~mm}$ height. The pressing portion included four independent components: control systems for axis pressure, confining pressure, rock pore pressure, and temperature. The servo control mode was adopted to ensure accuracy. These systems can be simultaneously moved by the pressure, deformation, and displacement controls. The maximum principal stress was determined by the axis pressure control system, where 


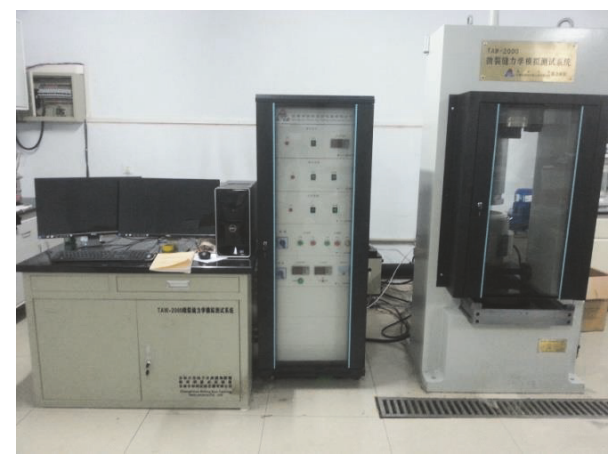

FIgURE 4: TAW-2000 triaxial pressure testing machine.

the pressure column was directly exerted on the surface of the samples. The maximum axial pressure is $2000 \mathrm{kN}$, and the error is $0.5 \%$. The minimum principal stress $\sigma_{-} 2$ and $\sigma \_3\left(\sigma \_2=\sigma \_3\right)$ were controlled by the confining pressure control system, where the confining pressure was produced by the hydraulic oil filling the cavity. The pore pressure was controlled by the pore system, where the pressure was exerted on the rock sample through the filling pressure fluid (pore pressure system range was $0-200 \mathrm{MPa}$ ). The instrument was also equipped with an individual climate control system, which enabled the continuous heating of the hydraulic oil and the temperature control, which regulated the rock sample temperature. The highest possible temperature is $200^{\circ} \mathrm{C}$, and the error is $0.5 \%$. The temperature control system accurately monitored the temperature of the confining pressure and sample temperatures during the test.

3.3. Experimental Procedure. The samples were divided into three groups, namely, complete undisturbed granodiorite (I), artificial vertical fractured granodiorite (II), and horizontal artificial cracked granodiorite (III). First, the samples were saturated to ensure a constant initial pore pressure. The three groups of test specimens were then pretreated. During the process, the rock pore pressure system was opened to air. At the same time, the axial and confining pressures were controlled within the range $0-60 \mathrm{MPa}$ under a $5 \mathrm{MPa} / \mathrm{min}$ rate, with three-time loading and unloading cycle to prevent negative factors from influencing the experimental system. After the pretreatment, the samples' confining and axial pressures reached $2 \mathrm{MPa}$, which was greater than the saturated water pressure at $150^{\circ} \mathrm{C}$. These conditions therefore prevented the water-saturated samples from overflowing through gasification. Second, the axial and confining pressures were repeatedly loaded and unloaded at $1 \mathrm{MPa} / \mathrm{min}$ within $2-55 \mathrm{MPa}$. Each cycle consisted of three stages: the uniform loading stage, the equilibrium stage after $15 \mathrm{~min}$, and the uniform unloading stage. Each complete cycle was processed under five different grades of temperature $\left(0,60,90,120\right.$, and $\left.150^{\circ} \mathrm{C}\right)$, and the temperature error range was $\pm 2^{\circ} \mathrm{C}$. The heating rate restriction within $2-5^{\circ} \mathrm{C} / \mathrm{min}$ was adopted to prevent rock damage and changes in microstructure from uneven heating. Additionally, strain, Young's modulus, and other rock parameters were measured during the test to ascertain
TABLE 3: Elastic parameters of the granodiorite specimens.

\begin{tabular}{lccc}
\hline $\begin{array}{l}\text { Poisson's } \\
\text { ratio } v\end{array}$ & $\begin{array}{c}\text { Young's modulus } \\
E(\mathrm{GPa})\end{array}$ & $\begin{array}{c}\text { Peak strength } \\
(\mathrm{MPa})\end{array}$ & $\begin{array}{c}\text { Yield strength } \\
(\mathrm{MPa})\end{array}$ \\
\hline 0.28 & 56.8 & 137.5 & 98 \\
\hline
\end{tabular}

the effects of the temperature and pressure coupling on rock mechanical parameters. After the pretreatment of the second group, the third group, which included the artificial vertical and horizontal fractured granodiorite samples (II and III), was tested. During the test, the axial and confining pressures were cyclically loaded and unloaded at a rate of $1 \mathrm{MPa} / \mathrm{min}$ within 2-55 MPa. Each complete cycle was processed under three different grades of temperature $\left(60,90\right.$, and $\left.120^{\circ} \mathrm{C}\right)$ at an error range of $\pm 2^{\circ} \mathrm{C}$ and the same heating rate at $2-5^{\circ} \mathrm{C} / \mathrm{min}$.

The two abovementioned comparison experiments performed under the same pressures and temperatures were designed to obtain the influence of fracture on rock mechanical parameters. Finally, undrained triaxial tests were performed on the three groups of samples to measure the strain. Biot's coefficient was calculated by the indirect method. The influences of temperature, effective pressure, rock inner fracture, and other factors on Biot's coefficient were determined from the experiments presented above.

\section{Results and Discussion}

Through rock uniaxial and triaxial compression testing, as well as rock hydrostatic testing, we obtained the mechanical parameter of the rock granodiorite samples. Moreover, with the steps elaborated in Section 3.3, we determined the relationships of the drained bulk modulus and Biot's coefficient with temperature, effective stress, and artificial fracture distribution.

4.1. Parameters of Rock Poisson's Ratio and Young's Modulus (Rock Uniaxial Test). The rock Poisson's ratio and Young's modulus $\mathrm{E}$ were measured under half of the peak strength by the rock uniaxial test. The results of the test are shown in Table 3.

4.2. Rock Framework's Bulk Modulus: Jacketed Hydrostatic Test. The indirect method for the determination of rock Biot's coefficient requires the knowledge of rock framework's bulk modulus. Unjacketed $\Delta p=\Delta P c$ refers to the condition that the pore pressure is equal to the confining stress. Hart and Wang [38] recommended two kinds of methods. One method utilizes jacketed saturated specimens and applies equivalent pore pressure and confining stress at the same rates to ensure that the rock framework particles are subjected to equivalent isotropic pressures. This strategy would then allow the accurate determination of the bulk strain of the rock matrix. Another applied unjacketed hydrostatic test uses the confining pressure oil saturation specimen to determine the static deformation induced by water pressure. We selected the former method to determine the rock framework's bulk modulus of the granodiorite samples obtained from the Jilin 

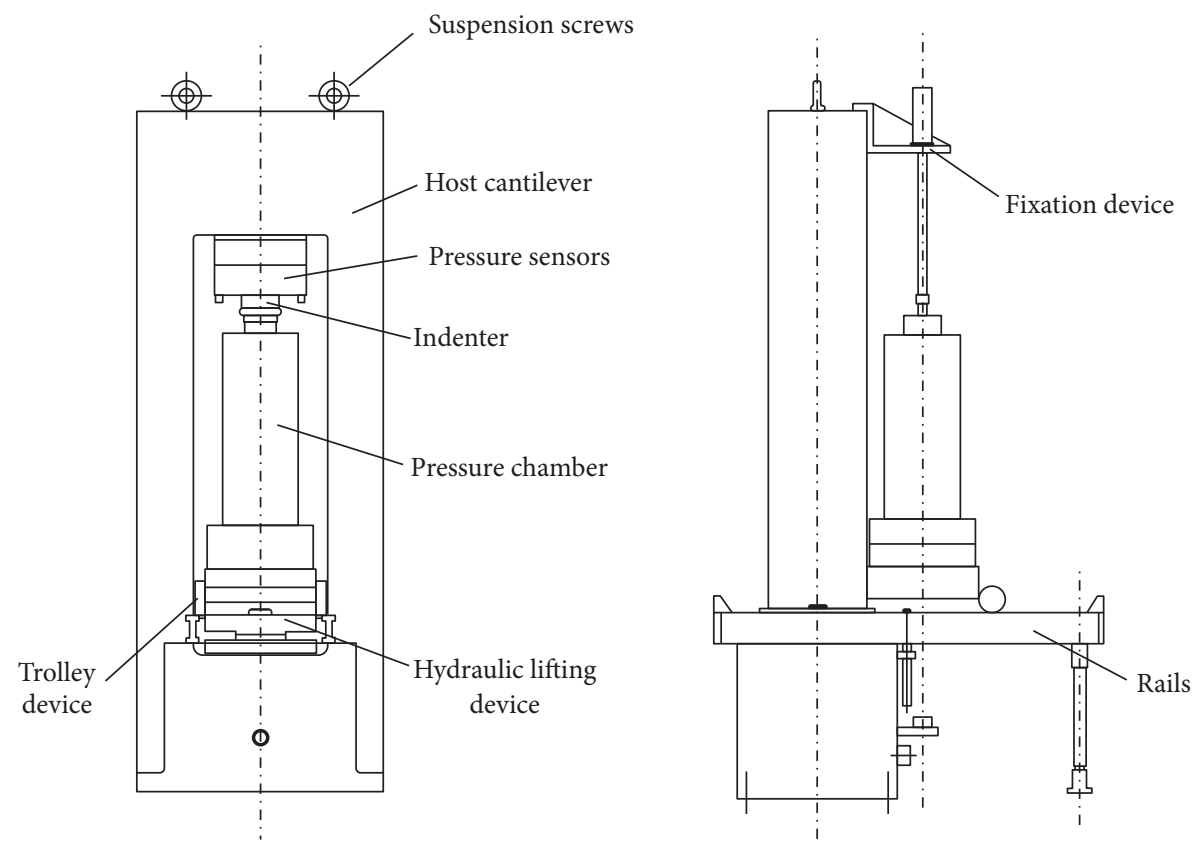

FIGURE 5: The main structural diagram of the experimental device.

TABLE 4: Framework's bulk modulus of the three groups of granodiorite.

\begin{tabular}{lccc}
\hline Groups & I & II & III \\
\hline $\begin{array}{l}\text { Rock framework's } \\
\text { bulk modulus (GPa) }\end{array}$ & 19.35 & 19.85 & 19.68 \\
\hline
\end{tabular}

Monkey Hill region. The findings are presented in Table 4. The three groups of granodiorite show similar grain bulk modulus. Considering the fact that the grain bulk modulus reflects the deformation of rock particles and the presence of fracture will not affect the stress condition of the rock particles in microfields. Thus the results of the three groups of samples are reasonable and the mean value of $19.5 \mathrm{GPa}$ is used to calculate Biot's coefficient.

\subsection{Inelasticity of the Late Indo-Chinese Epoch Granodior-} ite. Under the influence of temperature and stress, rock shows nonlinearity. Even in the stage of elastic loadingunloading, irreversible inelastic loading-unloading deformation is induced [6]. During our experiment, the samples were pretreated to eliminate the inelastic deformation. However, inelastic deformation may still be induced during the test because of temperature effects and plastic or creep deformation caused by prolonged pressure. To eliminate the influence of inelastic deformation, we measured the rock inelastic deformation during the loading-unloading test and modified the experimental results. Figure 6 shows the variation trends of rock bulk strain, confining stress, and temperature with time during the testing. The rock bulk strain was calculated using the radial and axial strains, which were measured by one radial strain sensor and four axial strain sensors. The findings revealed by Figure 6 is coincident with those

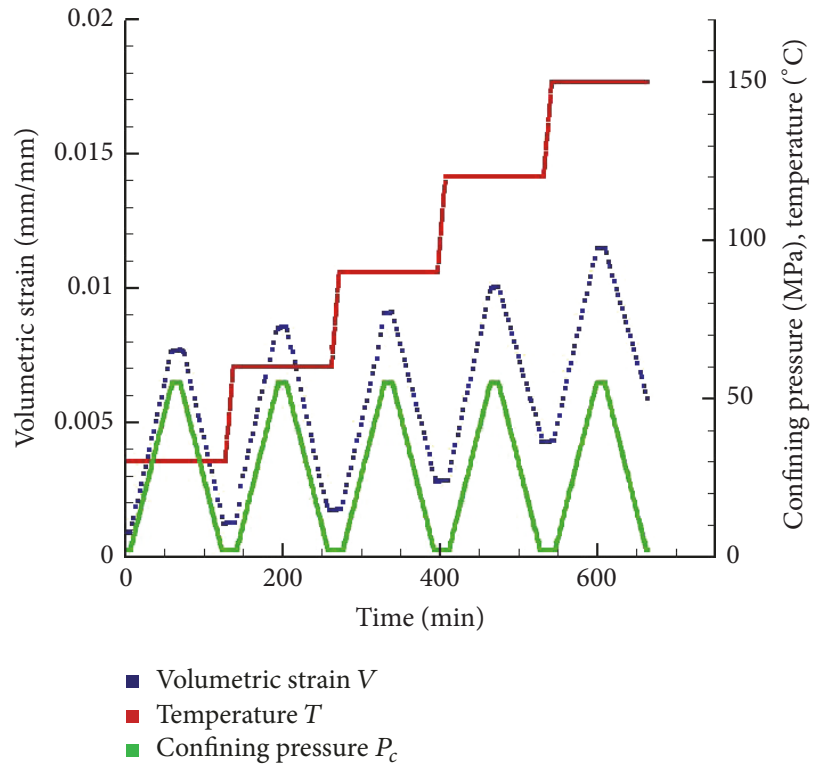

Figure 6: Inelastic deformation during the cyclic loading process.

of Walsh [39] and Brace [40], in which the rock assumed a complex, nonlinear property that was irreversible in the loading-unloading cycle. Furthermore, higher temperatures of the experimental environment yielded more apparent irreversibility.

As shown in Figure 6, the rock sample exhibits inelasticity as a consequence of increasing temperature and plastic or creep deformation during the stable process with loading. The results of inelastic deformation of loading-unloading cycles under different temperatures are displayed in Table 5. 
TABLE 5: Inelastic deformation under different temperatures.

\begin{tabular}{llllll}
\hline Temperature $\left({ }^{\circ} \mathrm{C}\right)$ & 30 & 60 & 90 & 120 & 150 \\
\hline $\begin{array}{l}\text { Inelastic deformation } \\
\left(\varepsilon^{p} \times 10^{-4} \mathrm{~mm} / \mathrm{mm}\right)\end{array}$ & 3.7 & 5.7 & 10.3 & 13.7 & 15.6 \\
\hline
\end{tabular}

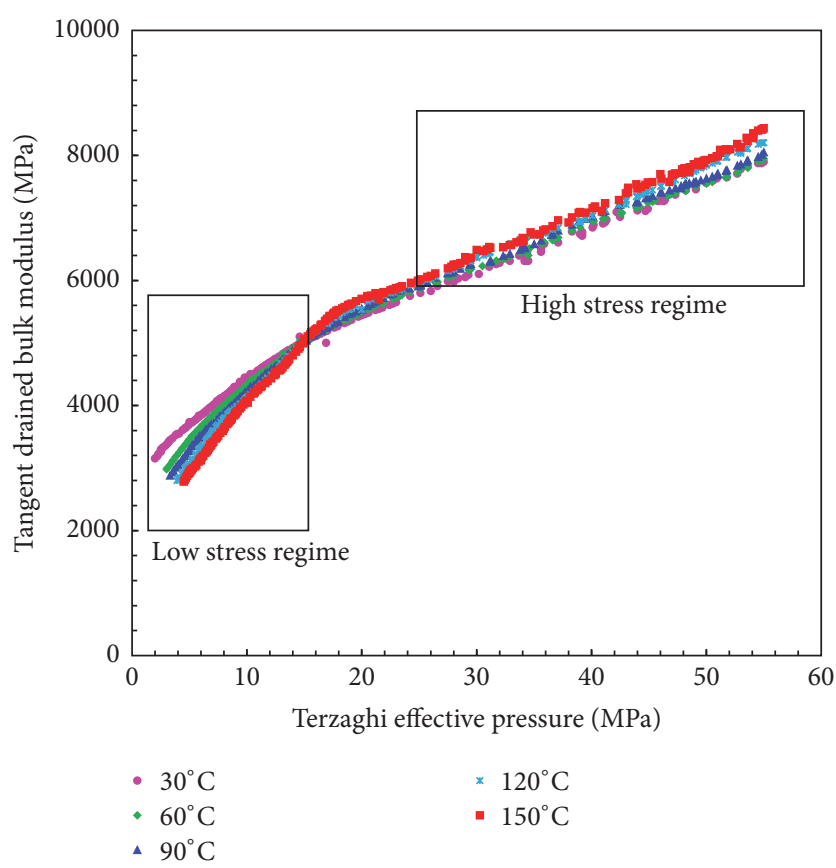

FIGURE 7: Relationship between drained bulk modulus and effective stress and temperature.

\subsection{Drained Bulk Modulus}

4.4.1. Influence of Temperature and Effective Stress on Rock Drained Bulk Modulus. The experiment was performed in accordance with the procedure presented in Section 3.3. The drained bulk modulus defined by the tangent modulus $K_{d}=\left(\partial P_{e} / \partial \varepsilon\right)_{T}$ was modified in accordance with the inelastic deformation shown in Table 5 before plotting the values into the curve. The relationships between drained bulk modulus and effective stress and temperature are shown in Figure 7.

Effective stress significantly influences the drained bulk modulus but the comparative effect of temperature is meager. As displayed in Figure 7, the bulk modulus increases with increasing effective stress when the temperature is constant, but the increasing rate varies when the temperature changes. As the effective stress increases from $3 \mathrm{MPa}$ to $55 \mathrm{MPa}$, the drained bulk modulus increases from $3.1 \mathrm{GPa}$ to $7.9 \mathrm{GPa}$ and from $2.5 \mathrm{GPa}$ to $8.2 \mathrm{GPa}$, respectively, at temperatures 30 and $150^{\circ} \mathrm{C}$. Interestingly, the variation trend of the drained bulk modulus with temperature is different, and the curve can be divided into three stages. Under a low stress range $(<12 \mathrm{MPa})$, the bulk modulus decreases with increasing temperature. Under a high stress range ( $>23 \mathrm{MPa})$, the bulk modulus increases with increasing temperature. The pressure range of $12-23 \mathrm{MPa}$ corresponds to a transitional range. We can conclude from Figure 8 that when temperature regularly changes from 30 to $150^{\circ} \mathrm{C}$, the bulk modulus reduces by as much as $15 \%$ in the low effective stress regime but increases as much as $12 \%$ in the high effective stress regime.

Results revealed that the temperature effects on granodiorite can be described by interrelations between the bulk modulus and the thermal expansion coefficient. The thermal expansion coefficient influenced by stress, as well as the heat-transfer processes influenced by path, affects the rock thermomechanical behavior. Different heat-transfer modes (constant pressure and constant volume) resulted in different trends of temperature effects on the bulk modulus of rocks and minerals. As observed previously by Carmichael [41], the temperature derivative of the isothermal bulk modulus is positive at constant volume (strain) and negative at constant pressure (stress). Thermal softening of minerals would occur at constant pressure, which results in a decrease in bulk modulus. The difference in thermal expansion coefficient between different minerals also contributed to the variations in rock bulk modulus during the heating process.

The temperature effects on bulk modulus under constant pressure can be viewed as the summation extrinsic and intrinsic changes. At the low stress regime, the heating process was dominated by a constant-pressure heat-transfer mode, and the rock particles expanded to the external space. In this case, the volumetric effects were dominant and softened the rock. By contrast, at the high stress regime, the path of the external expansion was constrained by high confining stress, and the rock particles shifted to internal expansion. In this condition, the pressure effects prevailed and stiffened the rock. Therefore, the competition between volume and pressure with respect to temperature contributes to the three stages of variation characteristics of the late Indogranodiorite. A transition region existed with a very wide variation range (12-23 MPa for the intact sample), and this can be explained by the anisotropic rock components.

4.4.2. Effect of Fractures on the Rock Drained Bulk Modulus. The experiment was repeated on the cracked specimens (vertical [II] and horizontal [III]), which were preprocessed to eliminate the effects of inelastic deformation as a consequence of incomplete crack closure. The results were also modified depending on the amount of creep deformation from long-time loading listed in Table 5. Figure 9 presents the variation of bulk modulus of specimens, including the cracks, with confining pressure and temperature. Along with the earlier test results, we plotted the curves of the variation of bulk modulus with effective stress in the three groups of specimens under fixed temperatures $\left(60,90\right.$, and $\left.120^{\circ} \mathrm{C}\right)$. This step was conducted to compare the different effects of fractures and fracture orientation on the rock bulk modulus.

By comparing the results of the cracked rock specimens with the former test findings, we obtained a similar conclusion. In particular, the intact rock specimens subjected to the same temperature yielded an increase in bulk modulus with increased effective pressure. Furthermore, under the same pressure, the variation trend of bulk modulus with temperature differs because of the varying stress; the drained bulk modulus decreases with increasing temperature in the low stress region and increases with increasing temperature 


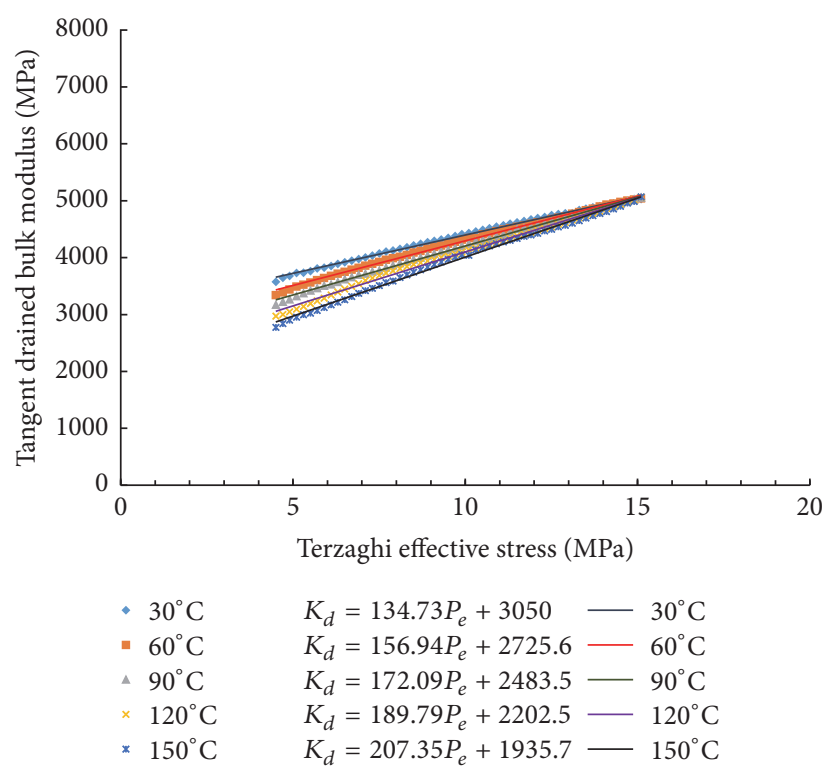

(a) Low stress region

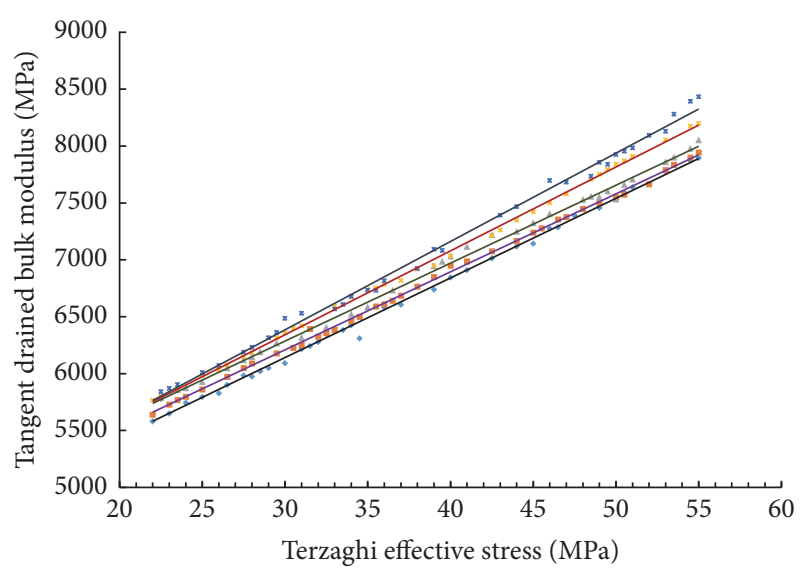

$\begin{array}{ll}\cdot 30^{\circ} \mathrm{C} & y=77.613 x+4056.6-30^{\circ} \mathrm{C} \\ =60^{\circ} \mathrm{C} & y=73.703 x+4130.6-60^{\circ} \mathrm{C} \\ \therefore 90^{\circ} \mathrm{C} & y=68.484 x+4231.5-90^{\circ} \mathrm{C} \\ * 120^{\circ} \mathrm{C} & y=68.533 x+4153-120^{\circ} \mathrm{C} \\ * 150^{\circ} \mathrm{C} & y=69.96 x+4042.4-150^{\circ} \mathrm{C}\end{array}$

(b) High stress region

FIGURE 8: Relationship between bulk modulus and temperature within different stress region.

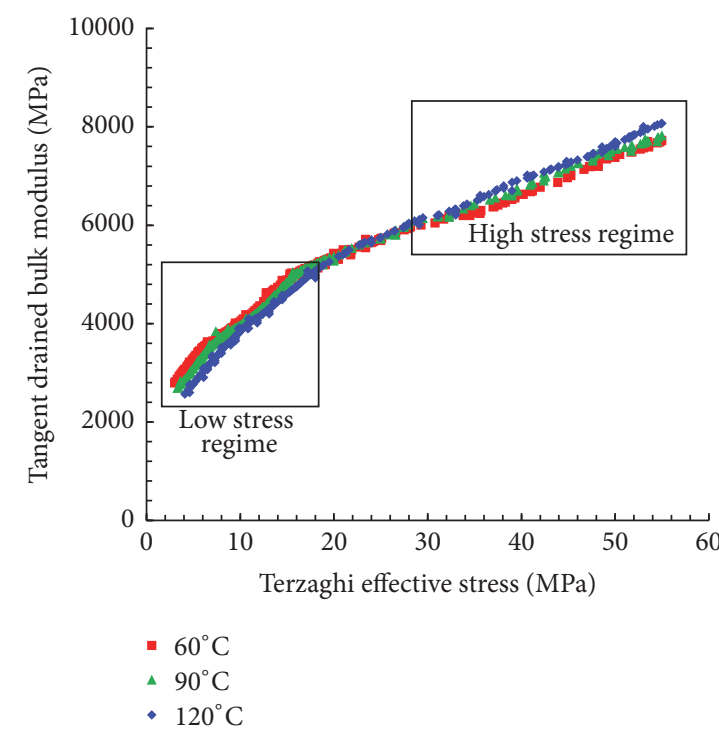

(a)

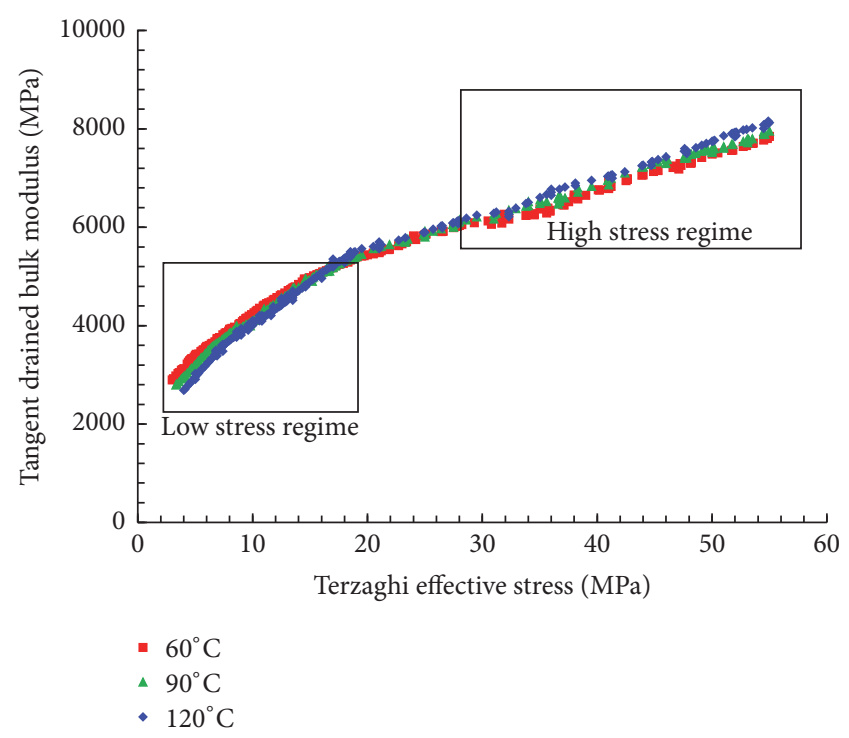

(b)

FIGURE 9: Relationships of drained bulk modulus with effective stress and temperature in cracked specimens: (a) specimens within vertical fractures and (b) specimens within horizontal fractures.

in the high stress region. Notably, the low stress region is 0-20 MPa and 0-17 MPa for the rock samples within horizontal fractures, whereas the high stress region is $33-55 \mathrm{MPa}$ for the rock within vertical fractures and 27-55 MPa for rock within horizontal fractures during this series of experiments.

The change laws for the intact and cracked rocks under different effective stresses and temperatures remained the same. The equivalent rock tangent bulk modulus decreased with temperature in the low pressure regime and increased with temperature in the high pressure regime. However, compared with intact rock, the cracked rock required additional pressure to alter the negative effect of temperature on the equivalent bulk modulus.

The cracked rocks mass consists of joints and isotropic block matrices separated by the joints. We assume that the thermodynamic parameters of the rock blocks belong to specimens II (containing vertical cracks) and III (containing horizontal cracks) remain the same with the intact specimens I. Because the prefabricated cracks of specimens II and III in this research extend to vertical and horizontal direction and the rocks are compressed by equal axial pressure and confining pressure, there is no displacement along the tangential 
direction of the fracture. Therefore, the existence of joints in the rock mass can be viewed as altering the mechanical boundary conditions of the blocks. On the microlevel a large number of discrete points exist within the scope of interface. Contact parts of rock particles can be considered as the constraint boundary with fixed pressure; while the discrete parts can be viewed as free boundary in a limited range, the rock particles could freely expand when heated. In the presence of equivalent low stress regime, for the rock blocks, the volumetric effects were more distinct than that of the intact specimens I. As a result, more pressure is needed to change the negative effects of temperature on the bulk modulus. As fractures developed further, greater pressure was needed for corresponding changes. In other words, the more area of the block is exposed to the fracture, the more boundary is changed, and more additional stress is needed. And the discrepancy between specimens II and III in the critical pressure that change the influence type of temperature on the bulk modulus is also consistent with this phenomenon.

We can also infer from Figure 9 that, in the same condition, the measured drained bulk modulus of the fractured specimens is lower than that of the intact specimens. Moreover, the drained bulk modulus of specimens within vertical fractures is the lowest. This phenomenon suggests that, in the same temperature and pressure conditions, the fractures have effects on the drainage bulk modulus (or equivalent bulk modulus). According to the equivalent deformation theory proposed by Goodman et al. [13], we take the joints as elastomer which can only be subjected to normal compression and shear deformation. The deformation of the rock mass is the summation of the deformation of rock bulks and the joints. However, the joints will decrease the elastic modulus no matter how we treat it as linear elasticity or nonlinear elasticity, so the bulk modulus will decrease simultaneously (Tang et al., 2007) [15]. The test results present in Figure 10 have also proved this conclusion. The discrepancy between the different types of specimens reflects the effects of the joints on the deformation parameters. We can find that, under the condition of high pressure in low temperature and the condition of low pressure in high temperature, the bulk modulus of the intact specimens is higher than the equivalent bulk modulus of the fractured specimens by $5 \%$ to $10 \%$, while in the other temperature and pressure conditions of this series of experiments, the gap of this parameter among this specimen is no more than 5\%. That is because the joints are not sensitive to hardening effects caused by pressure but to the softening effects by temperature. From the results we can conclude that the equivalent bulk modulus of the specimen with vertical fracture is lower than that of the horizontal fractured specimen's. And the results reflect that the influence degree increases with the trace of the fracture. There will be great influence of fracture on the deformation parameters with the further increasing fractures, although the impacts are not so much obvious in this research. Therefore, the effects investigation of fracture on bulk modulus under different temperature and pressure condition is meaningful.
4.5. Biot's Coefficients. With the results of the rock framework's bulk modulus (Table 4) and drained bulk modulus, we calculated Biot's coefficients by the indirect method as described by Hart and Wang [38]. The relationships of Biot's coefficient with Terzaghi effective stress and temperature are shown in Figures 11 and 12. The results show that the variation trend of Biot's coefficient remained consistent regardless of the absence or presence of cracks. Meanwhile, Figure 10 displays that the intact rock sample's Biot's coefficient decreases as the Terzaghi effective pressure increases from $0 \mathrm{MPa}$ to $60 \mathrm{MPa}$ at $30,60,90,120$, and $150^{\circ} \mathrm{C}$, respectively. On the other hand, Figure 12 shows the trend of Biot's coefficient with the change in Terzaghi effective pressure for the specimens within artificial fractures at 60,90 , and $120^{\circ} \mathrm{C}$. The variation trend is the same for the three different types of specimens.

As shown in Figure 12, Biot's coefficient of the granodiorite varies from 1 to 0.55 at the effective pressures of 0-60 MPa. Similar to the trend of the drained bulk modulus, the variation trend for Biot's coefficient with respect to temperature depends on the effective pressures. In the low stress regime, Biot's coefficient increases with increasing temperature. In the high stress regime, the value decreases with increasing effective pressure.

At lower stress, the changing trend of Biot coefficient with effective stress presents the nonlinear characteristics whereas in higher stress it shows linear behavior. This is mainly determined by the structure characteristics of the granodiorite. Granodiorite is characteristic with compact structure and low porosity. The microfractures close quickly when compressed, and the increasing stress makes the deformation from microfracture and porosity transfer to rock matrix. Because the fissures containing in fractured rocks in this paper is perpendicular to the axial and confining pressures, the deformation process of the specimens is shown as the summation of cracks closure and porosity and rock particles' compression when subjected to the same axial and confining pressure. The presence of fractures has not changed the fact that the deformation is elastic. And the cracked specimens can be treated as equivalent continuum media. Therefore the calculation of equivalent Biot coefficient is still within the scope of quasi-static theory of poroelasticity. The Biot coefficient and equivalent Biot coefficient for intact and cracked rock samples were compared under the same temperature and pressure condition as is shown in Figure 13. The cracks influence the equivalent Biot coefficient by two ways. On the one hand, fracture is of the stronger compressibility than the rock block due to the low proportion of skeletal contact leading to a higher Biot coefficient. On the other hand, for the rock block, the internal fracture boundary generates stress concentration at the contact section and weakens the real effective stress of the rock blocks resulting in a higher Biot coefficient.

\section{Summary and Conclusions}

A series of experiments were performed to study the effects of temperature and Terzaghi effective stress on the bulk modulus and Biot's coefficient of Indo-granodiorite rocks. The bulk modulus and Biot's coefficient of the intact as well as 


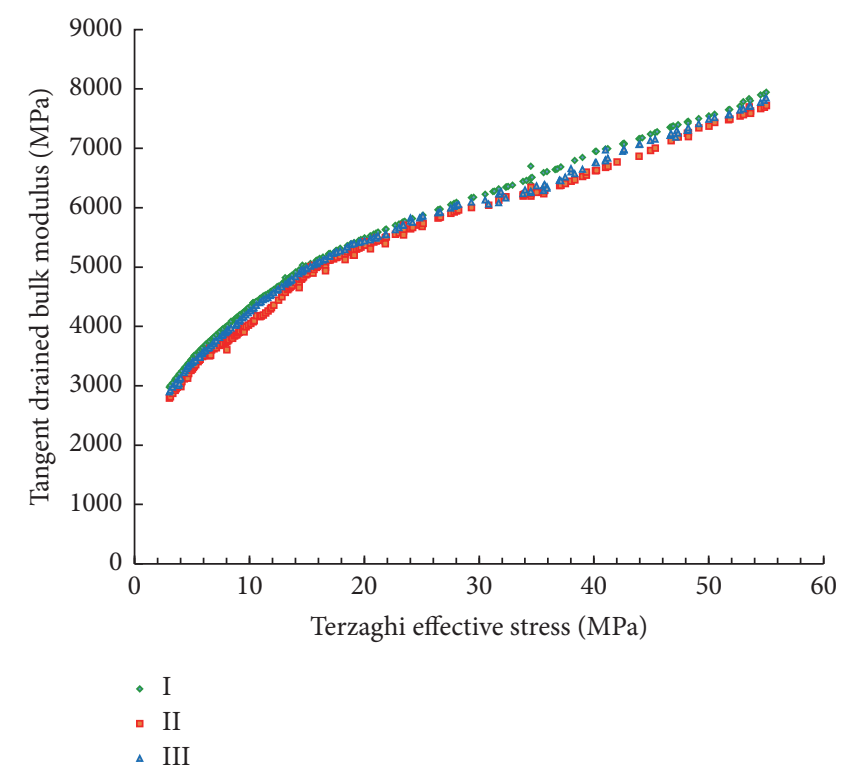

(a)

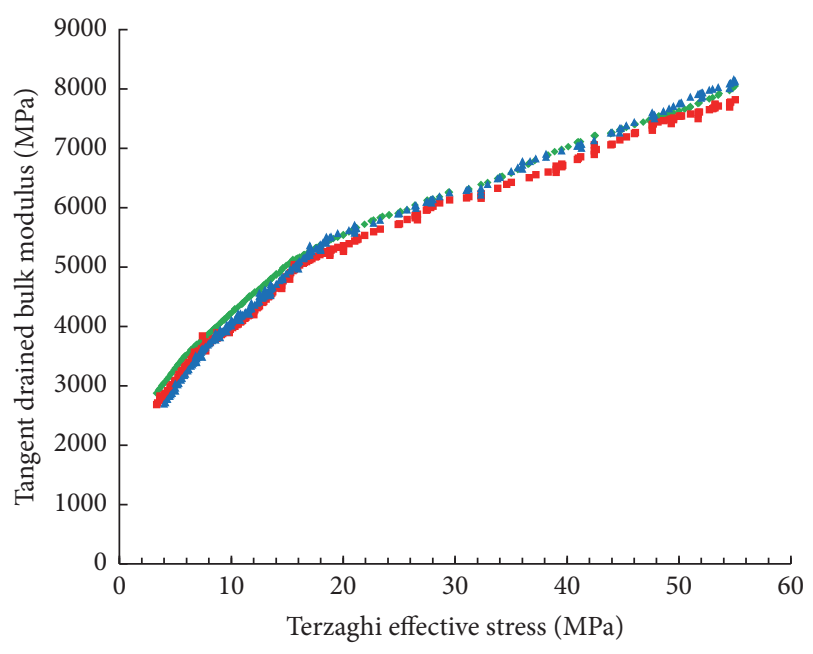

- I

. II

$\triangle$ III

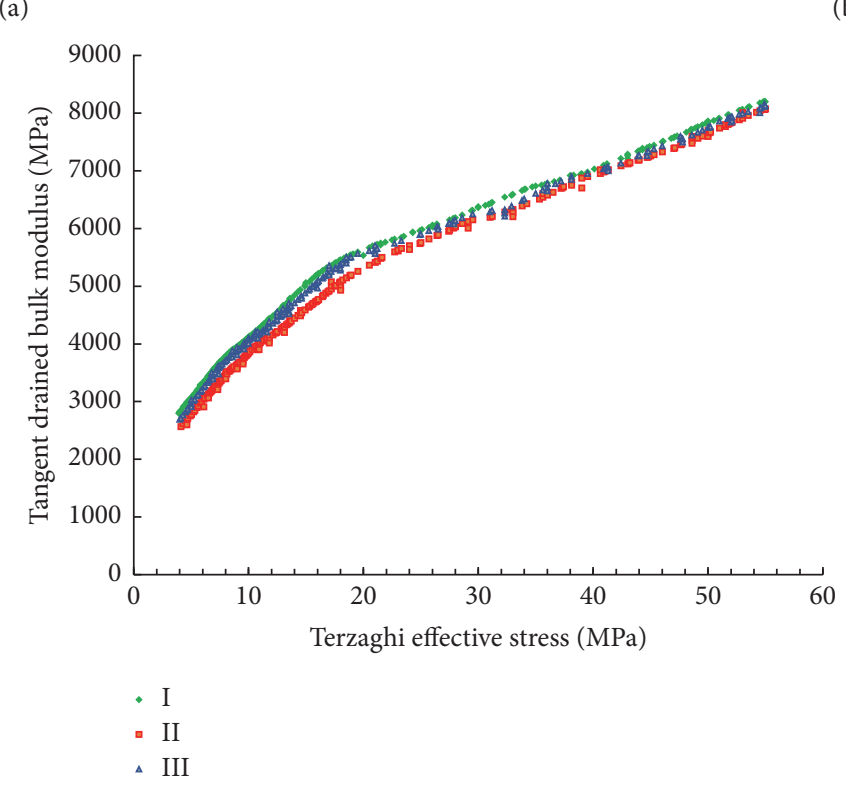

(b)

(c)

FIGURE 10: Experimental results of the specimens with different failure modes: relationship of drained bulk modulus with effective stress at (a) $60^{\circ} \mathrm{C}$, (b) $90^{\circ} \mathrm{C}$, and (c) $120^{\circ} \mathrm{C}$.

the cracked specimens were determined through the triaxial compression experiment. However, it should be noted that, according to the research of Goodman et al., we regard the cracked samples as equivalent continuum model and discuss the equivalent rock deformation parameters of them. The main conclusions drawn from this study can be summarized as follows:

(1) By means of experiments we compared the composition, structure, and degree of density of the granodiorite samples taken from Jilin Monkey Ridge and Gonghe Basin of Qinghai, and we found that the two samples are very similar in all respects. Given that sampling from Gonghe Basin is too difficult, the
Jilin Monkey Ridge samples are good alternatives to Republican Basin samples to investigate the thermomechanical behavior of the granodiorite.

(2) The drained bulk modulus was strongly affected by effective pressure. As the effective stress increases from $3 \mathrm{MPa}$ to $55 \mathrm{MPa}$, the drained bulk modulus increases from $3.1 \mathrm{GPa}$ to $7.9 \mathrm{GPa}$ and from $2.5 \mathrm{GPa}$ to 8.2 GPa, respectively, at temperatures 30 and $150^{\circ} \mathrm{C}$. Along with the change in temperature and pressure, the trend of Biot's coefficient countered the trend of the drained bulk modulus. When effective stress increased from 0 to $60 \mathrm{MPa}$ and temperature 


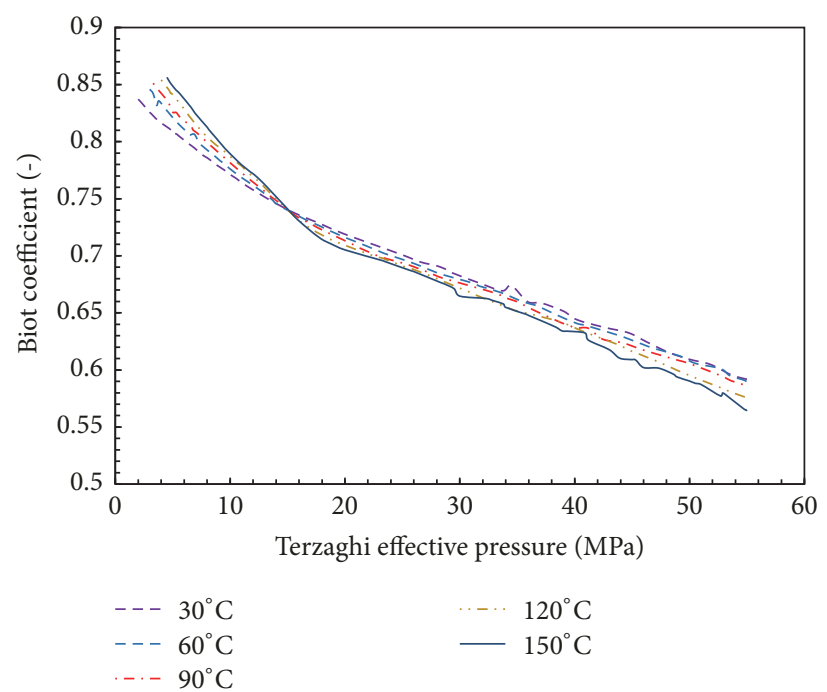

FIGURE 11: Biot's coefficient as a function of Terzaghi effective pressure for intact rock samples.

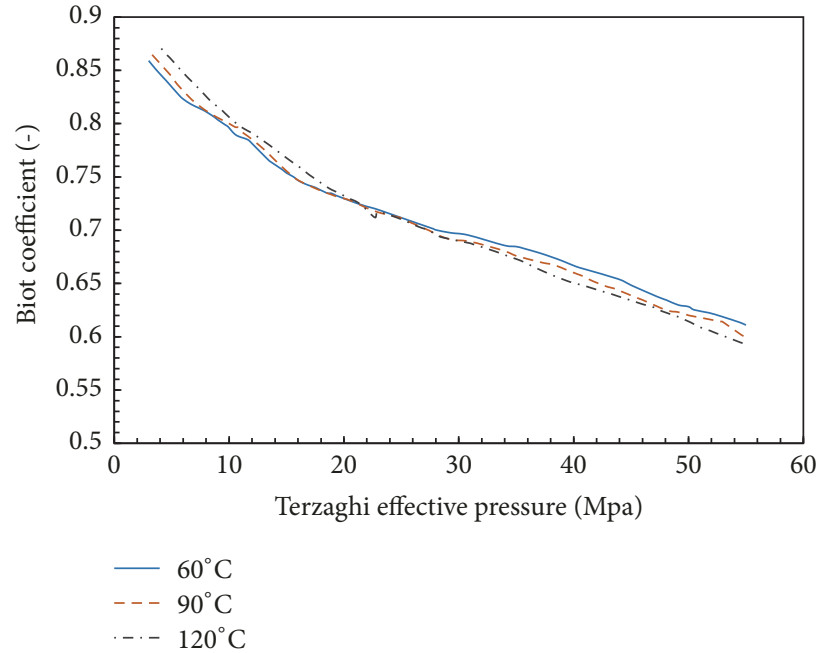

(a)

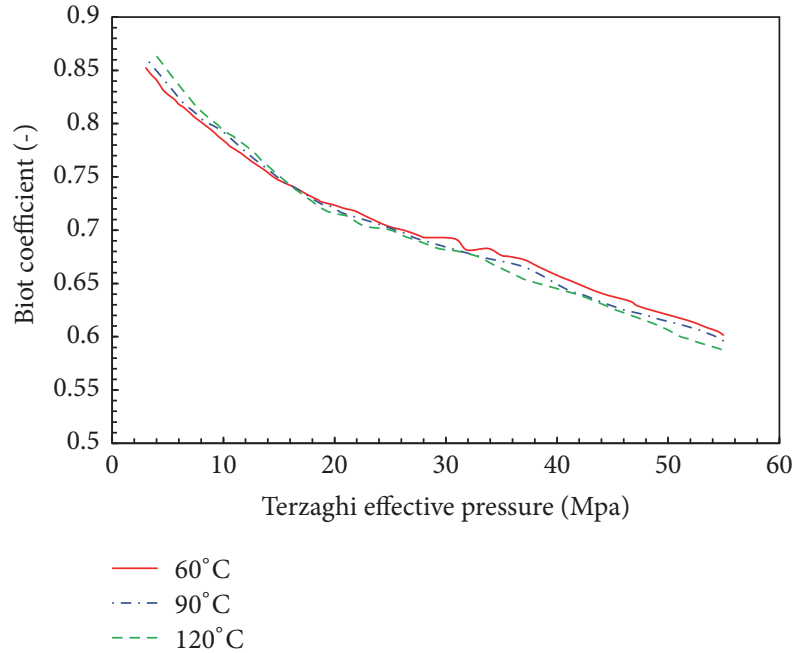

(b)

FIGURE 12: Biot's coefficient as a function of Terzaghi effective pressure for cracked rock samples: (a) specimens within vertical fractures and (b) specimens within horizontal fractures.

increased from $30^{\circ} \mathrm{C}$ to $150^{\circ} \mathrm{C}$, Biot's coefficient of granodiorite varied between 0.55 and 1 .

(3) The effect of temperature on thermomechanical parameters was more complicated than the pressure and can be divided into three stages: a low stress regime, where the temperature derivative of the drained bulk modulus was negative; a high stress regime, where the temperature derivative of the drained bulk modulus was positive; and a transitional regime. When the temperature regularly changed from 30 to $150^{\circ} \mathrm{C}$, the bulk modulus decreased as much as $15 \%$ in the low effective stress regime while increased as much as $12 \%$ in the high effective stress regime. Such reaction of the granodiorite to pressure and temperature can be explained by a potential competition between volume and pressure with respect to temperature.

(4) According to equivalent elastic theory, the joints are treated as elastic medium. And when subjected to heat and stress, they were not sensitive to hardening effects caused by stress but to the softening effects by temperature. In the fractured rock, the temperature and effective stress exerted effects on the samples' equivalent Biot coefficient and equivalent bulk modulus similar to those in the intact rock. However, the ranges of the low and high stress regimes differed. The cracked rock required more pressure to change the negative effect of temperature on the bulk modulus. 


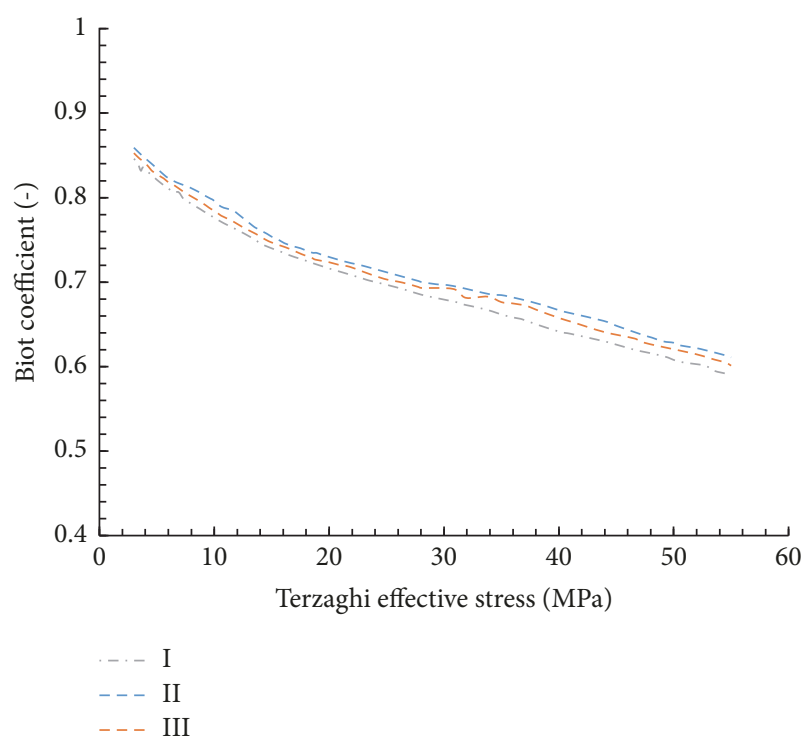

(a)

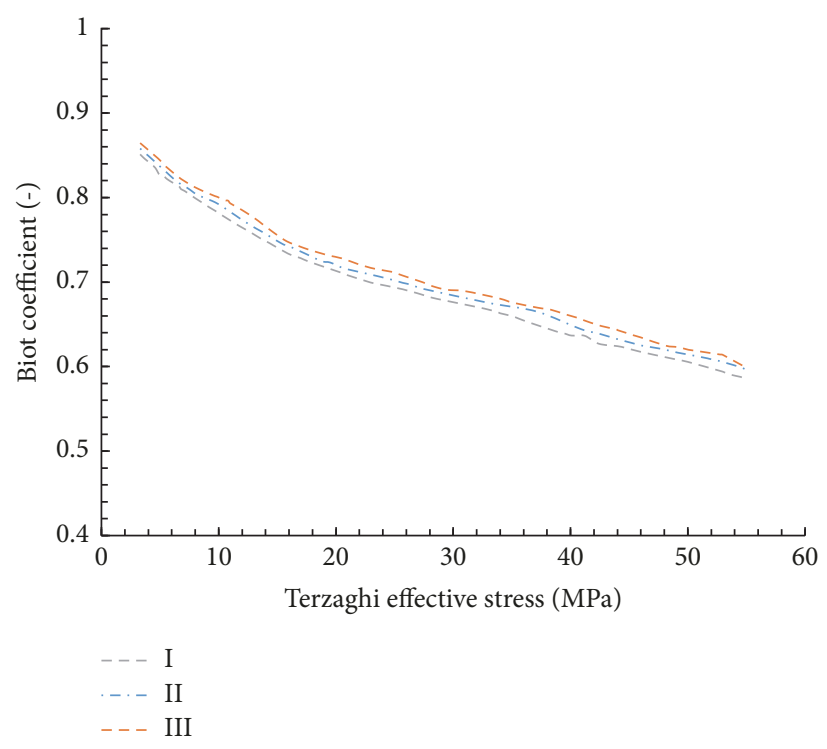

(b)

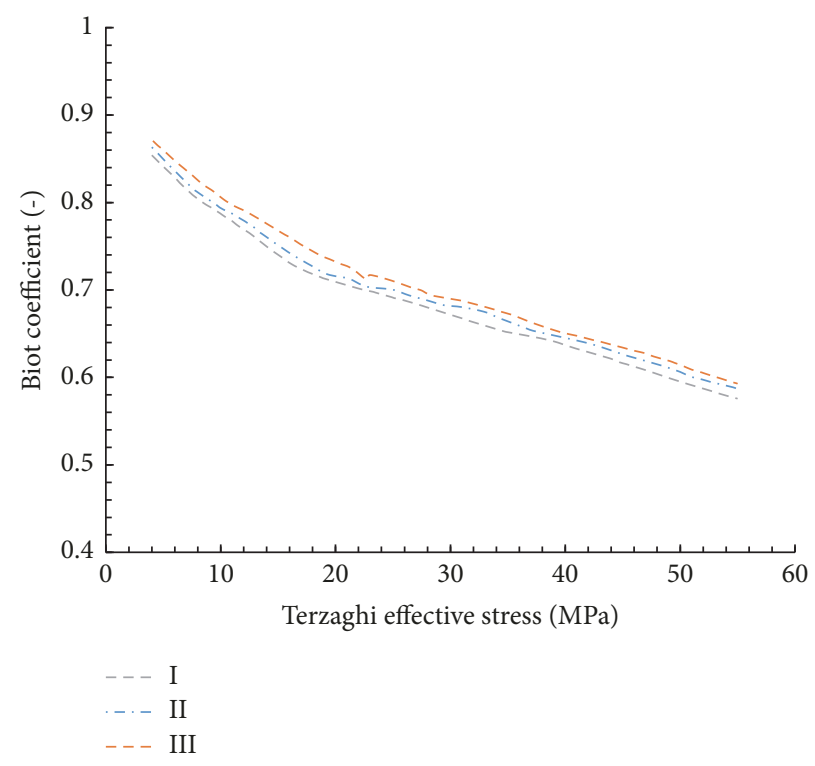

(c)

Figure 13: Biot's coefficient as a function of Terzaghi effective pressure for different types of granodiorite specimens at (a) $60^{\circ} \mathrm{C}$, (b) $90^{\circ} \mathrm{C}$, and (c) $120^{\circ} \mathrm{C}$.

\section{Conflicts of Interest}

The authors declare that there are no conflicts of interest regarding the publication of this paper.

\section{Acknowledgments}

This study was supported by the National High Technology Research and Development Program of China (863 Program) (no. 2012AA052801), the Natural Science Foundation of China (no. 41372238 and no. 41602243), Specialized Research
Fund for the Doctoral Program of Higher Education of China (no. 20110061110055), and Cooperative Project of Government and Jilin University: New Energy Technology Project (SXGJSF2017-5).

\section{References}

[1] M. A. Biot, "General theory of three-dimensional consolidation," Journal of Applied Physics, vol. 12, no. 2, pp. 155-164, 1941.

[2] K. Saliya, D. Grgic, R. Giot, and A. Giraud, “THM modeling of the $\mathrm{CO} 2$ injection in coal: Influence of biot's coefficient and 
langmuir's adsorption parameters," in Proceedings of the 5th Biot Conference on Poromechanics, BIOT 2013, pp. 648-657, July 2013.

[3] J. Handin, R. V. Hager, M. Friedman, and J. N. Feather, "Experimental Deformation of Sedimentary Rocks Under Confining Pressure: Pore Pressure Tests," AAPG Bulletin, vol. 47, pp. 717755, 1963.

[4] I. Song and J. Renner, "Hydromechanical properties of Fontainebleau sandstone: Experimental determination and micromechanical modeling," Journal of Geophysical Research: Solid Earth, vol. 113, no. 9, Article ID B09211, 2008.

[5] I. L. Fabricius and M. M. Alam, "Burial diagenesis of deep sea chalk as reflected in Biot's coefficient," in Proceedings of the 5th Biot Conference on Poromechanics, BIOT 2013, pp. 2414-2422, July 2013.

[6] M. Ramos da Silva, C. Schroeder, and J.-C. Verbrugge, "Poroelastic behaviour of a water-saturated limestone," International Journal of Rock Mechanics and Mining Sciences, vol. 47, no. 5, pp. 797-807, 2010.

[7] D. F. McTigue, "Thermoelastic response of fluid-saturated porous rock," Journal of Geophysical Research: Atmospheres, vol. 91, no. 9, pp. 9533-9542, 1986.

[8] J. R. Rice and M. P. Cleary, "Some basic stress diffusion solutions for fluid saturated elastic porous media with compressible constituents," Reviews of Geophysics, vol. 14, no. 2, pp. 227-241, 1976.

[9] M. C. Suárez-Arriaga, "Terzaghi's and Biot's poromechanics in terms of quaternions," in Proceedings of the 5th Biot Conference on Poromechanics, BIOT 2013, pp. 1488-1497, July 2013.

[10] M. M. Alam and I. L. Fabricius, "Change in Biot's effective stress coefficient of chalk during pore collapse," in Proceedings of the 5th Biot Conference on Poromechanics, BIOT 2013, pp. 23952403, July 2013.

[11] J. D. Blacic, P. H. Halleck, P. D’Onfro, and R. E. Riecker, "Thermomechanical properties of Galesville sandstone," in Mechanical Behavior of Crustal Rocks, vol. 24 of Geophysical Monograph Series, pp. 153-159, American Geophysical Union, Washington, DC, USA, 1981.

[12] A. Hassanzadegan, G. Blöcher, G. Zimmermann, and H. Milsch, "Thermoporoelastic properties of Flechtinger sandstone," International Journal of Rock Mechanics and Mining Sciences, vol. 49, pp. 94-104, 2012.

[13] R. E. Goodman, R. L. Taylor, and L. T. Brekke, "A model for the mechanics of jointed rock," Journal of the Soil Mechanics and Foundation Division, ASCE, vol. 94, no. 3, pp. 637-659, 1968.

[14] Z. Wu and Z. Xianhong, "Elastic models of jointed rock masses," Chinese Journal of Geotechnical Engineering, vol. 9, no. 4, pp. 3344, 1987 (Chinese).

[15] J. Han, S. Li, S. Li, X. Tong, and W. Li, "Study of deformation characteristic of rock mass with multiple persistent crack sets," Chinese Journal of Rock Mechanics and Engineering, vol. 30, no. 1, pp. 3319-3325, 2011 (Chinese).

[16] Y. Zhao, P. Cao, Y. Wang, and Y. Liu, "Coupling model of seepage-damage-fracture in fractured rock masses and its application," Chinese Journal of Rock Mechanics and Engineering, vol. 27, no. 8, pp. 1634-1643, 2008.

[17] D. Hu, H. Zhou, and S. Xie, "Study of Biot's coefficients of marble during plastic deformation phase," Rock and Soil Mechanics, vol. 30, no. 12, pp. 3727-3734, 2009 (Chinese).

[18] X. Tan and H. Konietzky, "Numerical study of variation in Biot's coefficient with respect to microstructure of rocks," Tectonophysics, vol. 610, pp. 159-171, 2014.
[19] Y.-J. Zhang, Z.-W. Li, Z.-W. Yu, L.-L. Guo, X.-P. Jin, and T.-F. $\mathrm{Xu}$, "Evaluation of developing an enhanced geothermal heating system in northeast China: Field hydraulic stimulation and heat production forecast," Energy and Buildings, vol. 88, pp. 1-14, 2015.

[20] Y.-J. Zhang, L.-L. Guo, Z.-W. Li, Z.-W. Yu, T.-F. Xu, and C.Y. Lan, "Electricity generation and heating potential from enhanced geothermal system in Songliao Basin, China: Different reservoir stimulation strategies for tight rock and naturally fractured formations," Energy, vol. 93, pp. 1860-1885, 2015.

[21] L. Guo, Y. Zhang, Z. Yu, Z. Hu, C. Lan, and T. Xu, "Hot dry rock geothermal potential of the Xujiaweizi area in Songliao Basin, northeastern China," Environmental Earth Sciences, vol. 75, no. 470, pp. 1-22, 2016.

[22] Y.-C. Zeng, J.-M. Zhan, N.-Y. Wu, Y.-Y. Luo, and W.-H. Cai, "Numerical simulation of electricity generation potential from fractured granite reservoir through vertical wells at Yangbajing geothermal field," Energy, vol. 103, pp. 290-304, 2016.

[23] I. Tomac and M. Gutierrez, "Coupled hydro-thermomechanical modeling of hydraulic fracturing in quasi-brittle rocks using BPM-DEM," Journal of Rock Mechanics and Geotechnical Engineering, vol. 9, no. 1, pp. 92-104, 2017.

[24] H. Hofmann, T. Babadagli, and G. Zimmermann, "Numerical simulation of complex fracture network development by hydraulic fracturing in naturally fractured ultratight formations," Journal of Energy Resources Technology-Transactions of the ASME, vol. 136, no. 4, 2014.

[25] S. N. Pandey and V. Vishal, "Sensitivity analysis of coupled processes and parameters on the performance of enhanced geothermal systems," Scientific Reports, vol. 7, no. 12, pp. 1-14, 2017.

[26] L. Bai, Experimental Analysis of Rock Biot Coefficient And Engineering Application of Geological Disposal of Carbon Dioxide, Jilin University, Changchun, China, 2016.

[27] W. Lu and Y.-Y. Xiang, "Experiments and sensitivity analyses for heat transfer in a meter-scale regularly fractured granite model with water flow," Journal of Zhejiang University SCIENCE A, vol. 13, no. 12, pp. 958-968, 2012.

[28] E. A. Roeloffs, "Fault stability changes induced beneath a reservoir with cyclic variations in water level," Journal of Geophysical Research: Atmospheres, vol. 93, no. B3, pp. 2107-2124, 1988.

[29] J. G. Berryman, "Effective stress for transport properties of inhomogeneous porous rock," Journal of Geophysical Research: Atmospheres, vol. 97, no. B12, pp. 17409-17424, 1992.

[30] Y. Gueguen and M. Bouteca, "Propriétés mécaniques des roches: pression de pore et effets d'échelle," Oil \& Gas Science and Technology, vol. 54, no. 6, pp. 703-714, 1999.

[31] R. W. Zimmerman, W. H. Somerton, and M. S. King, "Compressibility of porous rocks," Journal of Geophysical Research: Solid Earth, vol. 91, no. B12, pp. 12765-12777, 1986.

[32] M. Bouteca, D. Bary, and V. Maury, "An experimental study of the contribution of thepore volume change to production within the framework of Biot theory," in Proceedings of the 1993 society of core analysts technical conference, pp. 1-12, 1993.

[33] V. Levin, "Thermal expansion coefficients of heterogeneous materials," Mekhanika Tverdogo, vol. 2, pp. 93-94, 1967.

[34] J. G. Berryman, "Mixture theories for rock properties," in American Geophysical Union Handbook of Physical Constants, T. J. Ahrens, Ed., pp. 205-228, AGU, New York, NY, USA, 1995.

[35] S. Ghabezloo and J. Sulem, "Stress dependent thermal pressurization of a fluid-saturated rock," Rock Mechanics and Rock Engineering, vol. 42, no. 1, pp. 1-24, 2009. 
[36] R. Campanella and J. Mitchell, "Influence of temperature variations on soil behaviour," Journal of the Soil Mechanics and Foundations Division, vol. 94, no. SM3, pp. 709-734, 1968.

[37] V. V. Palciauskas and P. A. Domenico, "Characterization of drained and undrained response of thermally loaded repository rocks," Water Resources Research, vol. 18, no. 2, pp. 281-290, 1982.

[38] D. J. Hart and H. F. Wang, "Laboratory measurements of a complete set of poroelastic moduli for Berea sandstone and Indiana limestone," Journal of Geophysical Research: Solid Earth, vol. 100, no. B9, pp. 17741-17751, 1995.

[39] J. B. Walsh, "The effect of cracks on the compressibility of rock," Journal of Geophysical Research: Atmospheres, vol. 70, no. 2, pp. 381-389, 1965.

[40] W. F. Brace, "Volume changes during fracture and frictional sliding: A review," Pure and Applied Geophysics (PAGEOPH), vol. 116, no. 4-5, pp. 603-614, 1978.

[41] R. S. Carmichael, Handbook of Physical Properties of Rocks, CRC-Press, 1989. 


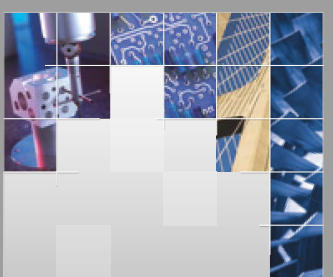

\section{Enfincering}
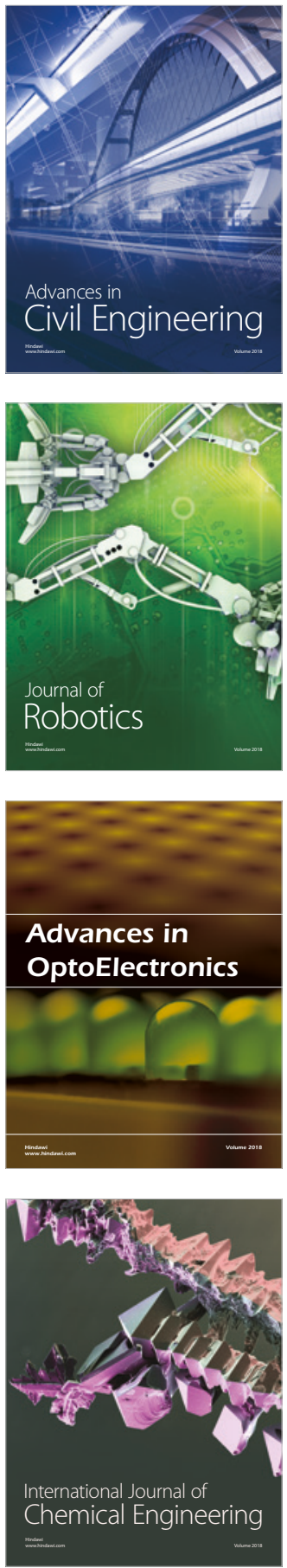

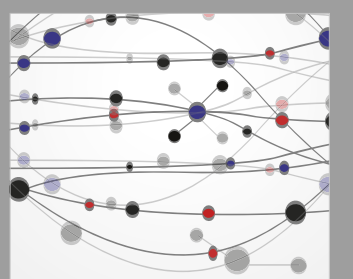

\section{Rotating \\ Machinery}

The Scientific World Journal

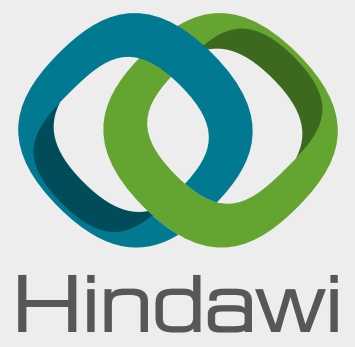

Submit your manuscripts at

www.hindawi.com
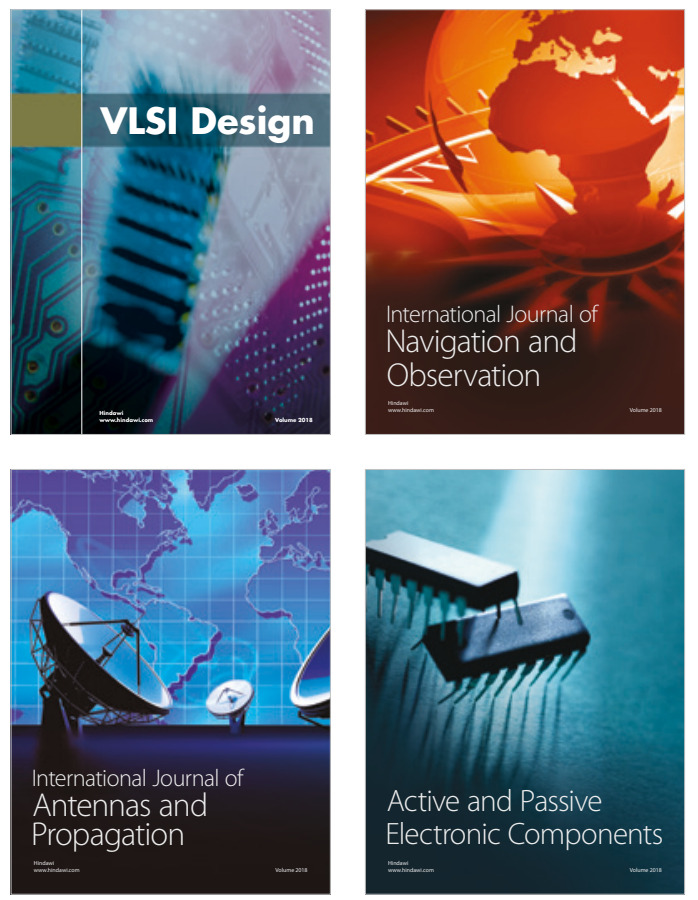
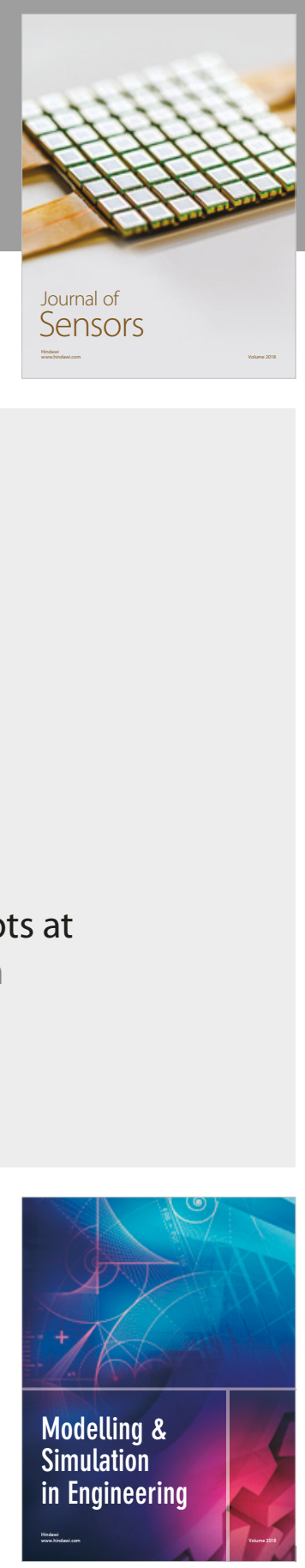

\section{Advances \\ Multimedia}
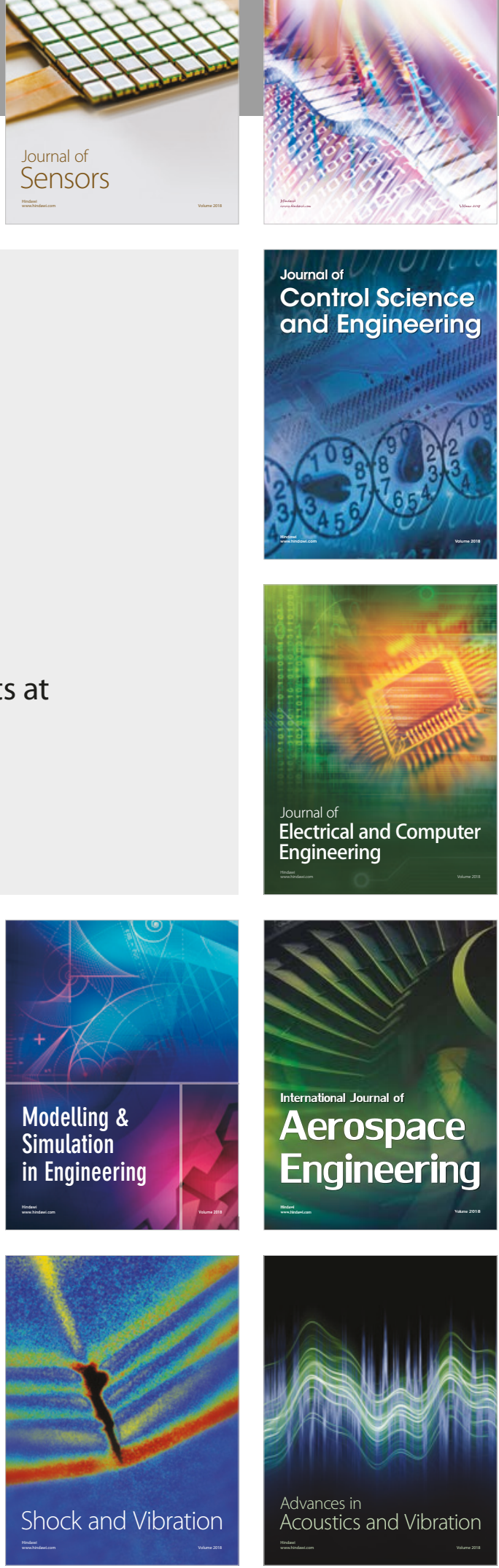